\title{
Interactions of the channel forming peptide alamethicin with artificial and natural membranes
}

\author{
MANOJ K. DAS and P. BALARAM \\ Molecular Biophysics Unit, Indian Institute of Science, Bangalore 560012, India \\ MS received 9 July 1984 \\ Abstract. Alamethicin and related a-aminoisobutyric acid peptides form transmembrane \\ channels across lipid bilayers. This article briefly reviews studies on the effect of alamethicin on \\ lipid phase transitions in lipid bilayers and on mitochondrial oxidative phosphorylation. \\ Fluorescencepolarization studies, employing 1,6-diphenyl-1,3,5-hexatriene as a probe, suggest \\ that alamethicin fluidizes lipid bilayers below the phase transition temperature, but has little \\ effect above the gel-liquid crystal transition point. Alamethicin is shown to function as an \\ uncoupler of oxidative phosphorylation in rat liver mitochondria. The influence of alamethicin \\ on mitochondrial respiration is modulated by the phosphate ion concentration in the medium. \\ Classical uncoupling activity is evident at low phosphate levels while inhibitory effects set in at \\ higher phosphate concentrations. Time-dependent changes in respiration rates following \\ peptide addition are rationalized in terms of alamethicin interactions with mitochondrial \\ membrane components.
}

Keywords. Alamethicin; membrane channels; mitochondrial uncouplers; mitochondrial inhibitors; peptide-lipid interactions; membranes.

\section{Introduction}

Alamethicin and related a-aminoisobutyric acid (Aib)containing peptides of microbial origin, form voltage dependent channels across lipid bilayer membranes (Mathew and Balaram,1983a, 1984;Jung et al., 1981;Mueller and Rudin, 1968; Mueller, 1976; Hall, 1978).These systems provide an excellent model for investigating the molecular events involved in the formation and gating of membrane channels. Over the past few years considerable effort has been devoted towards establishing the structural characteristics of these channel forming peptides (Nagaraj and Ealaram, 1981; Prasad and Balaram, 1984; Toniolo et al., 1983; Smith et al., 1981;Fox and Richards, 1982; Banerjee et al., 1983; Schmitt et al., 1982).Figure 1 lists a few representative sequences for this class of peptides. The general consensus of these studies has favoured an overall helical conformation for these polypeptides, with channels being formed by aggregation of peptides in the lipid bilayer, generating supramolecular structures having a central aqueous core (figure 2) (Iqbal and Balaram, 1981; Fox and Richards, 1982).

An important feature of $3_{10}$ or $\alpha$-helical peptide structures is the existence of a macrodipole moment along the helix axis, with the amino and carboxy terminii serving

Abbreviations used Aib, a-Aminoisobutyric;DPH, 1,6-diphenyl-1,3,5-hexatriene; P, polarization; DPPC, dipalmitoylphosphatidyl choline; DMPC, dimyristoylphosphatidyl choline; $P_{i}$, phosphate ions; FCCP, carbonykyanide-p-trifluoromethoxyphenylhydrazone. 


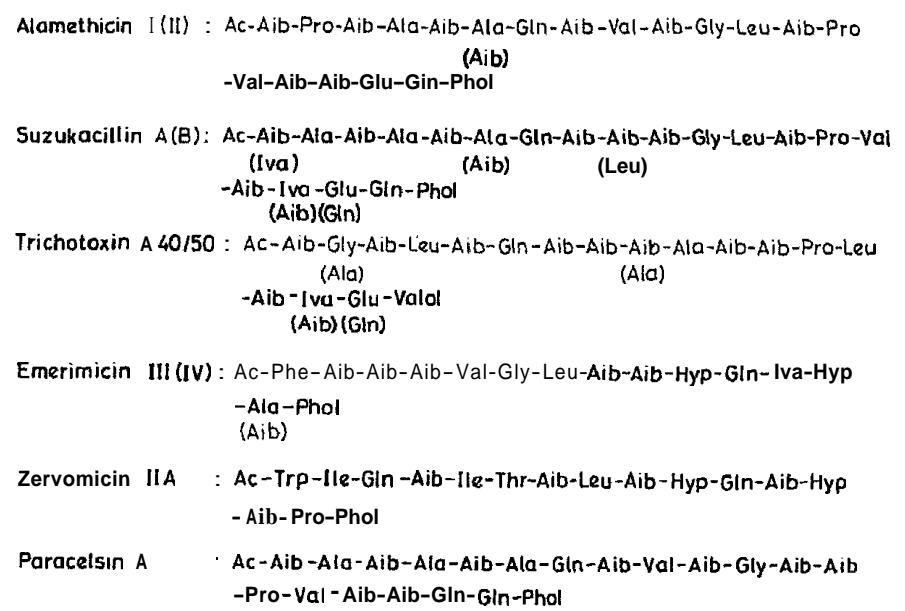

Figure 1. Representative sequences of Aib containing membrane channel forming polypeptides. All the naturally occurring peptides in this class are mixtures of very closely related polypeptides, A more complete listing of sequences may be found in Mathew and Balaram (1984). A discussion of separation and sequencing studies, with a critical analysis of heterogeneity of sequences is given by Bruckner and Przybylski (1984).

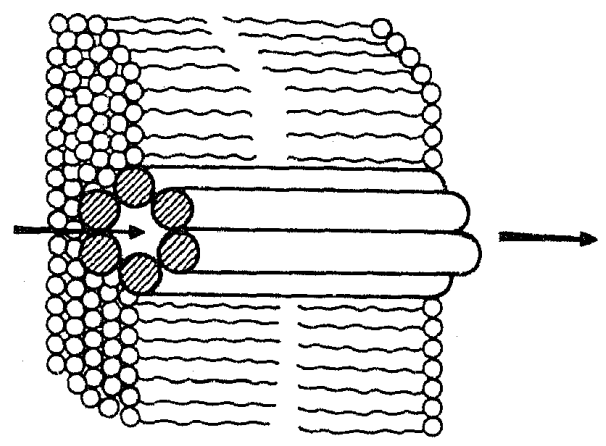

Figure 2. Schematic representation of transmembrane channel formation by lipid phase aggregation of helical, rodlike peptide structures.

as the positive and negative ends of the dipole, respectively (Wada, 1976; Hol et al., 1981).In the case of alamethicin and the related peptide trichotoxin, dipole moments of 40-75 D have been estimated experimentally in solvents like octanol and dioxane (Yantorno et al., 1982;Schwarzand Savko,1982a,b; Schwarzet al., 1983).Dipole-dipole interactions may therefore play an important role in stabilizing aggregates of membrane spanning peptides in the lipid phase (Mathew and Balararn, 1983a,b, 1984). The conductivity characteristics of channels may then be modulated by changing aggregate size and also by altering transmembrane orientations of peptid emonomers in the aggregate, thus changing the net dipole moment of the channel. Two recent models, which attempt to rationalisc available experimental observations on potential dependent channelformation by alamethicin and data on pore state fluctuations, have ascribed a key role to helix dipole interactions (Mathew and Balaram, 1983b; Balaram, 1983;Boheim et al., 1983;Jung et al., 1983).Figure 3 summarises the main features of a model for alamethicin channels proposed from this laboratory. It is clear that both peptide-peptide and peptide-lipid interactions will determine channel properties. For 


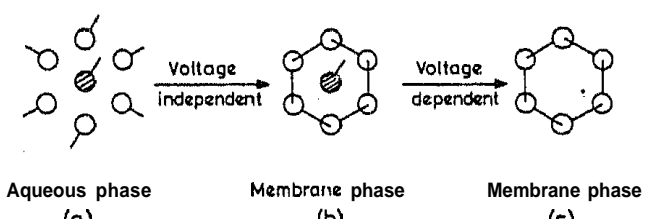

(a)

(b)

(c)

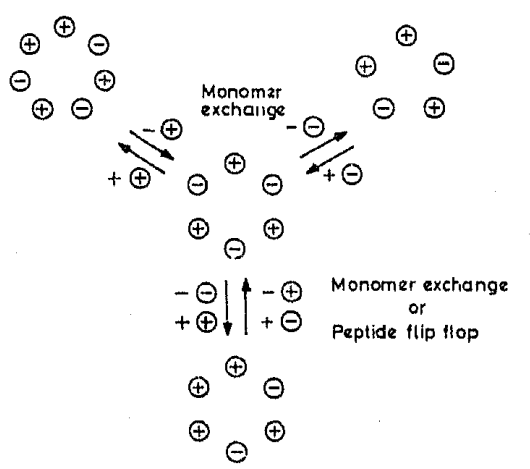

(d)

Figure 3. Proposed model for voltage dependent channel formation by alamethicin. (a) Aggregate of peptide helices in the aqueous phase. The projection represents a polar sidechain, presumably Gln (7). (b) Membrane phase aggregate formed by insertion of peptide aggregate into the bilayer and rotation about the helix axis of each molecule to form intermolecular hydrogen bonds. A central peptide molecule (core piece) blocks the channel. (c) Voltage dependent extrusion of the core piece which would be a macrodipole. This is facilitated by lack of intermolecular hydrogen bonds to its neighbours. (d) Model for pore state transitions in which net dipole state or aggregation number changes. This occurs either by monomer exchange or peptide flip-flop across the bilayer (Mathew and Balaram, 1983b; Balaram, 1983).

example, pore state lifetimes could be determined by membrane lipid 'fluidity'; a more mobile lipid phase permitting facile peptide diffusion, leading to rapid formation and breakdown of functional aggregates. The effects of alamethicin and related amphipathic, helical peptides on natural membranes may be influenced by dipole-dipole interactions of the peptide with transmembrane segments-of integral proteins.

Detailed accounts of the structural characteristics of alamethicin and its synthetic fragments (Nagaraj and Balaram, 1981; Prasad and Balaram, 1984; Jung et al., 1981; Fax and Richards 1982) and discussions of membrane modifying properties are available (Mathew and Balaram 1983a, 1984). There have been relatively few reports on the effects of alamethicin incorporation on the structural properties of artificial and natural membranes (Chapman et al., 1969; Hauser et al., 1970; Finer et al., 1969; Lau and Chan, 1974,1975,1976;McIntosh et al., 1982;Irmscher and Jung, 1977;Bessler $\boldsymbol{e t}$ al., 1979), in contrast to the large volume of electrochemical data on black lipid membrane systems. The observations that alamethicin pores result in the unmasking of inner surface membrane enzymes in diverse systems (Jones et al., 1977,1980; Lad and White, 1979; Besch et al., 1977;Herman et al., 1980; Misselwitz et al.. 1979; Bonnafous et al., 1982; Monneron and d'Alayer, 1980; Bessler et al., 1979), suggest that large channels can form in natural membranes. These, in turn, permit transmembrane passage of bulky, charged substrates. The observation that alamethicin (Takaishiet al., 1980; Mathew et al., 1981a) and its synthetic fragments (Mathew et al., 1981a,b, 1982) 
uncouple mitochondrial oxidative phosphorylation, has been interpreted in terms of effective dissipation of $\mathrm{H}^{+}$gradients across the inner mitochondrial membrane by alarnethicin channels (Mathew et al., 1981a, 1982). This article briefly reviews recent results from this laboratory on the effects of alamethicin on artificial lipid bilayers and oxidative phosphorylation in mitochondria.

\section{Peptide-lipid interactions}

Fluorescence polarization studies, using 1,6-diphenyl-1,3,5-hexatriene (DPH) as a probe, can be employed to monitor the physical state of lipid bilayers. The gel-liquid crystal phase transition, is accompanied by a substantial increase in the disorder of the hydrocarbon chains of lipid molecules, resulting in increased rotational and translational mobilities of dissolved spectroscopicprobes. In the case of DPH incorporated into lipid bilayers, there is a large increase in rotational reorientation rates above the phase transition, leading to a significantfall in the value of the fluorescencepolarization (P).DPH has therefore, been extensively employed as a probe of the microviscosity of artificial and natural membranes (Shinitzky and Barenholz, 1978).

Figure 4 shows the results of experiments designed to monitor the effects of peptide

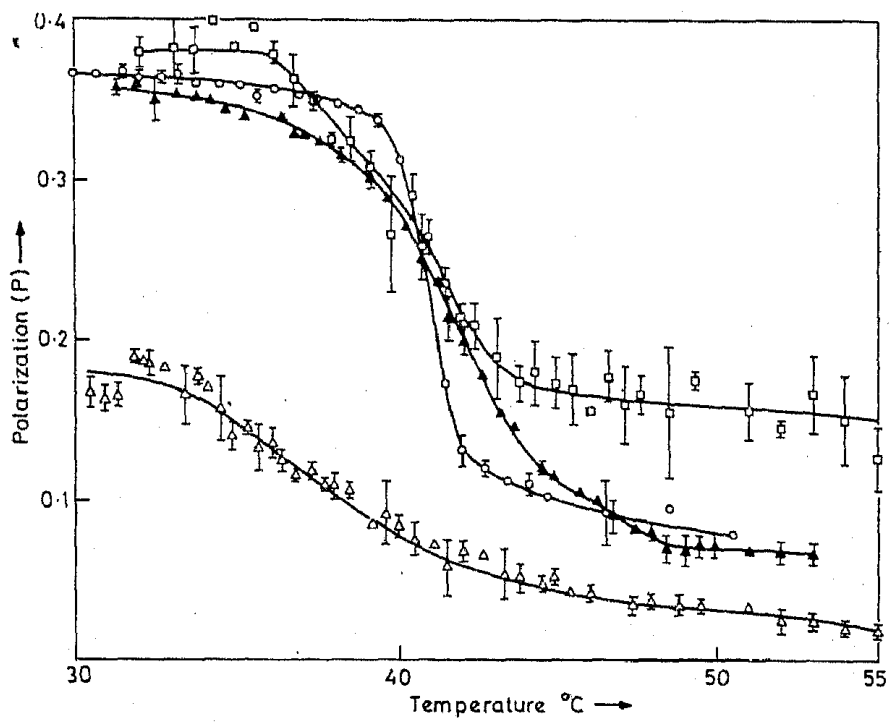

Figure 4. Effect of peptides on the phase transition of DL- $\alpha$-DPPC liposomes monitored using DPH fluorescence polarization $\mathrm{P}$ as a probe. (O), DPPC; $(\square)$, DPPC + suzukacillin fragment $16 G$, (A), DPPC + alamethicin fragment Z-1-17-OH, (A), DPPC + alamethicin. Peptide: lipid mol ratio is 1:2.3. DPPC (1.09 $\mu \mathrm{mol})$ and peptide $(0.46 \mathrm{pol})$ were taken in $\mathrm{CHCL}_{3}-\mathrm{CH}_{3} \mathrm{OH}$ $(2: 1 \mathrm{v} / \mathrm{v})$ and the solventevaporated in a stream of nitrogen. The film was dried under vacuum, $2 \mathrm{ml} 5 \mathrm{mM}$ HEPES-100 $\mathrm{mM} \mathrm{NaCl}, \mathrm{pH} 7.0$ was added and the solution heated to $45^{\circ} \mathrm{C}$ and mixed vigorously on a vortex mixer. The suspension was sonicated until it became optically clear (Branson B-12 sonifier, output power $40 \mathrm{~W}$ ). The solution was centrifuged to remove particulate matter. $1 \mathrm{ml}$ of $2 \mu \mathrm{M} \mathrm{DPH}$ in the same buffer was added to $1 \mathrm{ml}$ of the liposome solution. The solutions were incubated at $45^{\circ} \mathrm{C}$ for $2 \mathrm{~h}$ to permit DPH incorporation. Polarization values were measured on a Perkin-Elmer MPF-44 A fluorescence spectrometer equipped with a polarization accessory. $\lambda_{\mathrm{ex}}=\mathbf{3 6 0} \mathrm{nm}, \lambda_{\mathrm{em}}=430 \mathrm{~nm}$. Temperature control was accomplished using a thermostatted cell assembly and a controlled temperature water circulator. Polarization values are averages of $\mathbf{4}$ determinations. 
incorporation on the thermal phase transition of dipalmitoylphosphatidyl choline (DPPC)liposomes. In the absence of peptide DPPC shows a sharp transition centered at $41^{\circ} \mathrm{C}$, with $\mathbf{P}$ values of $0.36-0.37$ below the transition and values of $\sim 0.08$ above the transition temperature. Incorporation of $\mathbf{3 0}$ mole per cent of alamethicin, dramatically perturbs the bilayer, resulting in a large drop in the $\mathrm{P}$ value even at $30^{\circ} \mathrm{C}$. On heating the lipid-peptidecomplexes, a broad transition is observed, with very low $\mathbf{P}$ values ( $\sim 0: 03$ ) at higher temperatures. Alamethicin thus appears to "fluidize" the gel phase of DPPC liposomes. A 17-residue synthetic fragment of alamethicin (benzyloxycarbonyl-AibPro-Aib-Ala-Aib-Ala-Gln-Aib-Val-Aib-Gly-Leu-Aib-Pro-Val-Aib-Aib-OH, Z-1-17$\mathbf{O H}$ ) and a 16-residue suzukacillin fragment (Boc-Ala-Aib-Ala-Aib-Aib-Cln-Aib-LeuAib-Gly-Leu-Aib-Pro-Val-Aib-Aib-OMe, 16G) were also examined. Figure 4 demonstrates that both these peptides have a much less pronounced effect on DPPC bilayers, as compared to alamethicin. In both cases there is a detectable broadening of the phase transition. It is of interest to note that the limiting $\mathrm{P}$ value at high temperature is significantly greater in the case of the neutral peptide $16 \mathrm{G}$, as compared to DPPC alone or in the presence of alamethicin or Z-1-17-0H. This may imply that $16 \mathrm{G}$ forms a relatively more tightly packed peptide lipid complex above the lipid phase transition temperature. Both the $\mathbf{1 6}$ and 17 residue peptides have been shown to form channels which transport $\mathrm{Ca}^{2+}$ in synthetic liposomes (Nagaraj et al., 1980; Iqbal, 1982). Their activity is, however, less than that observed for alamethicin. Peptide aggregation in both aqueous and lipid phases may play an important role in channel formation (Mathew and Balaram, 1983a,b, 1984; Mathew et al., 1982).It has been shown that the ease of aqueous phase aggregation is dependent on peptide chain length, longer peptides associating at lower concentrations than shorter fragments (Mathew et al., 1981b, 1982). The differential effects of the peptides on the lipid phase transition may reflect differencesin their surface activity or 'detergent like' properties, with alamethicin acting as a more effective perturbant than its shorter fragments. It should be noted that peptide effects on the lipid phase transition have been monitored at significantly higher peptide-lipid ratios, than those employed in cation translocation studies (Nagarajet al., 1980; Mathew et al., 1982).

Figure 5 compares the effect of increasing alamethicin concentration on the $\mathrm{P}$ values observed for DPH incorporated in DPPC, dimyristoylphosphatidyl choline (DMPC)

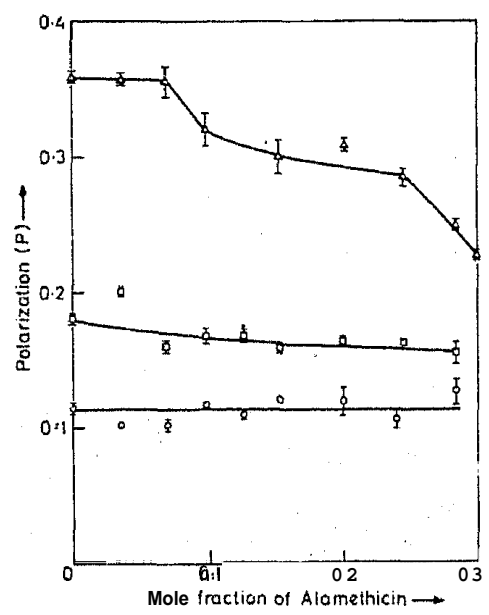

Figure 5. Influence of alamethicin on the fluorescence polarization of DPH incorporated into different liposomes, (a), DPPC: (口), DMPC; (O), egg yolk lecithin. Lipid-peptide suspensions $(28: 1)$ were prepared as described in the legend to figure 4. Further increases of peptide concentration were accomplished by injection of $1 \mu \mathrm{l}$ of an alamethicin stock solution $(9.8 \mathrm{mM})$ into the lipid suspensions, followed by sonication. All other conditions are as described for figure 4. 
and egg lecithin vesicles. The phase transition temperatures for these systems, in the absence of peptide are $41^{\circ} \mathrm{C}, 23^{\circ} \mathrm{C}$ and -7 to $-15^{\circ} \mathrm{C}$, respectively (Ladbrooke and Chapman, 1969). The experiments summarized in figure 5 were carried out at $\mathbf{2 5}^{\circ} \mathbf{C}$. Peptide incorporation lowers the $\mathrm{P}$ value only in the case of DPPC, but is largely without effect on DMPC and egg lecithin, which are already in a fluid state above their respective transition temperatures. Peptide molecules appear to be easily incorporated into fluid bilayers, without further significant perturbation of lipid packing. This observation is of relevance for studies of peptide interaction with natural membrane systems, where lipid phases are generally in a 'fluid' state.

\section{Peptide effects on mitochondria}

The energy derived from substrate oxidation in mitochondria is utilized for phosphorylating ADP in mitochondria. The chemiosmotic hypothesis visualizes energy transduction via an electrochemical $\mathrm{H}^{+}$and potential gradient across the inner mitochondrial membrane as a means of coupling the oxidation and phosphorylation reactions (Mitchell, 1966). Substances which break down transmembrane $\mathrm{H}^{+}$or ion gradients (protonophores or ionophores) can serve to uncouple oxidative phosphorylation (Green, 1977).Channel forming peptides would therefore be expected to act as uncouplers and indeed one of the earliest characterized uncouplers was the peptide antibiotic, gramicidin A (Hotchkiss, 1944). The initial observation that the natural peptides alamethicin and hypelcin uncouple oxidative phosphosylation in rat liver mitochondria (Takaishi et al., 1980)was extended to demonstrate qualitatively similar activities for synthetic alarnethicin and its shorter fragments (Mathew et al., 1981a,b, 1982). Figure 6 shows representative experiments on the effect of various peptide

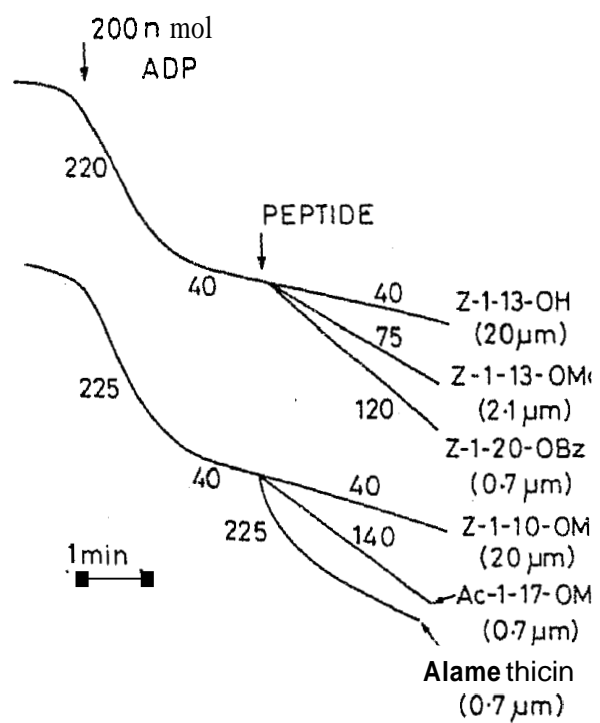

Figure 6. Effect of alamethicin and its fragments on state 4 respiration of rat liver mitochondria. Substrate used was succinate. Numbers shown on traces indicate $\mathrm{O}_{2}$ consumption in $n g$ atoms $\mathrm{O} / \mathrm{min} / \mathrm{mg}$ mitochondrial protein. Peptide nomenclature: P-1-n-c where Pis the protecting group, $n$ the number of residues in the alamethicin sequenceand $c$ the C-terminal group. $\mathbf{Z}=$ benzyloxycarbonyl, $\mathrm{Ac}=$ acetyl, $\mathrm{OMe}=$ methyl ester, $\mathrm{OBz}=$ benzyl ester (Mathew and Balaram, 1984). 
fragments on oxygen consumption by mitochondria. Uncoupling efficiency depends on chain length, with the longer peptides acting at lower concentrations. An interesting feature is that the uncoupling activity of alamethicinis dependent on the concentration of phosphate ions $\left(P_{i}\right)$ in the medium. Significant enhancement of respiratory rates is observed at $P_{i}$ concentrations between 1 and $10 \mathrm{mM}$ (Takaishi et al., 1980). While $P_{i}$ dependent uncoupling has been observed in the case of the cationic cyanine dye uncouplers (Terada,1979)and peptide carrier ionophores like valinomycin (Moore and Pressman, 1964), the role of $P_{i}$ in this process remains to be clearly understood (Terada, 1981).

We have therefore examined the influence of a wide range of $P_{i}$ concentrations $(2.5-100 \mathrm{mM})$ on the effects of alamethicin on oxidative phosphorylation. Figure 7 shows the effect of alamethicin on state 4 mitochondria at various peptide and $P_{i}$ concentrations. Upto $25 \mathrm{mM} P_{i}$ alamethicin behaves as an uncoupler, stimulating respiration, at peptide concentrations varying from $0 \cdot 045-0 \cdot 3 \mu \mathrm{M}$. At a higher range of $P_{i}$ concentrations $(50-100 \mathrm{mM})$ there is an initial stimulation followed by a distinct reduction in the respiratory rate, suggestive of an inhibitory effect. This tendency is particularly evident in the results for alarnethicin concentrations of $0.075-0.15 \mu \mathrm{M}$, at $100 \mathrm{mM} P_{i}$. A further feature of interest is that at $2.5 \mathrm{mM} P_{i}$ and low alamethicin concentration $(0.075 \mu \mathrm{M})$, there is an initial lag period before stimulation of $\mathrm{O}_{2}$ consumption sets in (figure 7a, trace i).

Figure 8 compares the effect of alamethicin, with those of the bee venom peptide melittin $\left(\mathrm{H}_{2} \mathrm{~N}\right.$-Gly-Ile-Gly-Ala-Val-Leu-Lys-Val-Leu-Thr-Thr-Gly-Leu-Pro-Ala-

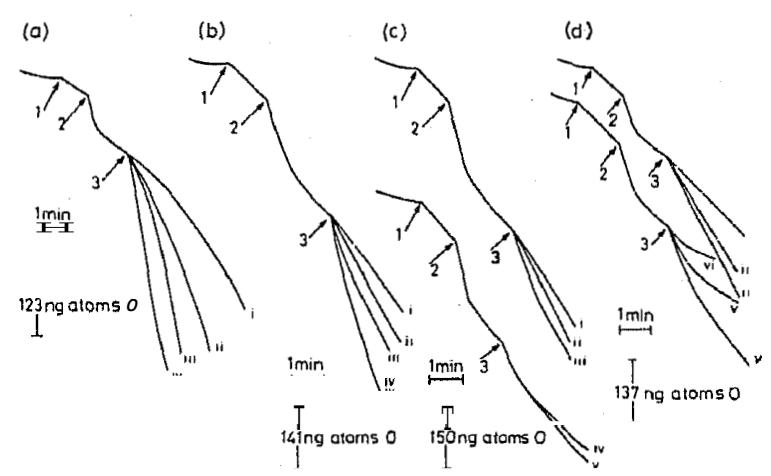

Figure 7. Effect of alamethicin on state 4 respiration in rat liver mitochondria suspended in media with $P_{i}$ concentrations of (a) $2.5 \mathrm{mM}$, (b) $25 \mathrm{mM}$, (c) $50 \mathrm{mM}$ and (d) $100 \mathrm{mM}$. Alamethicin concentrations are: (a) $0.075 \mu \mathrm{M}$ (i), $0.105 \mu \mathrm{M}$ (ii), $0.15 \mu \mathrm{M}$ (iii), $0.30 \mu \mathrm{M}$ (iv). (b) $0.045 \mu \mathrm{M}$ (i), $0.075 \mu \mathrm{M}$ (ii), $0.150 \mu \mathrm{M}$ (iii), $0.30 \mu \mathrm{M}$ (iv). (c) $0.03 \mu \mathrm{M}$ (ij, $0.045 \mu \mathrm{M}$ (ii), $0075 \mu \mathrm{M}$ (iii), $0.15 \mu \mathrm{M}$ (iv), $03 \mu \mathrm{M}$ (v). (d) $0.0075 \mu \mathrm{M}$ (i), $0.015 \mu \mathrm{M}$ (ii), $003 \mu \mathrm{M}$ (iii), $0.045 \mu \mathrm{M}$ (iv), $0.075 \mu \mathrm{M}$ (v), $0.15 \mu \mathrm{M}$ (vi). Mitochondrial protein concentration $\sim 0.48 \mathrm{mg} / \mathrm{ml}$. Mitochondria were isolated from rat liver by the procedure of Pedersen et al. (1978) and suspended in $2 \mathrm{ml}$ of assay medium, containing $\mathrm{D}(-)$ mannitol $(220 \mathrm{mM})$, sucrose $(70 \mathrm{mM})$, HEPES $(2 \mathrm{mM})$, EGTA $(0.5 \mathrm{mM}), \mathrm{MgCl}_{2}(2.5 \mathrm{mM})$ and $\mathrm{KH}_{2} \mathrm{PO}_{4}$ at varying concentrations as indicated. $\mathrm{pH}$ was adjusted to 7.0. Oxygen consumption was monitored using a Hansatech oxygen electrode at $\mathbf{3 3}^{\circ} \mathrm{C}$. Points $1,2,3$ indicate additions of succinate ( $7.5 \mathrm{mM}$ ), ADP and alamethicin, respectively, ADP was added at concentrations of (a) $72 \mu \mathrm{M}$, (b) $90 \mu \mathrm{M}$, (c) $110 \mu \mathrm{M}$ and (d) $77 \mu \mathrm{M}$. Alamethicin stock solutions were prepared in ethanol and added volumes did not exceed $5 \mu$. 
(a) Alamethicin

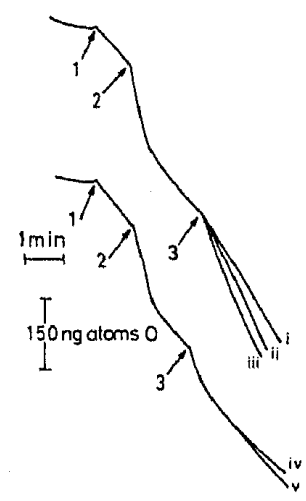

(b) Melittin

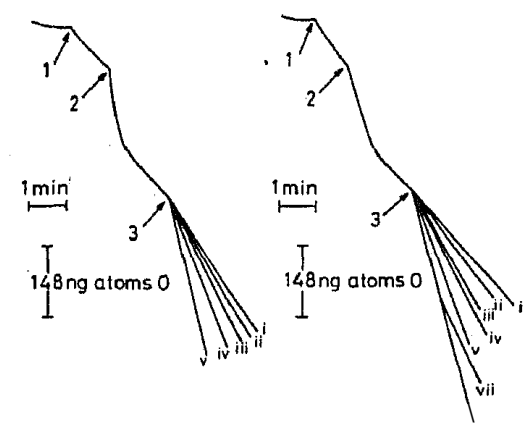

Figure 8. Acomparison of the effects of alamethicin(a), melittin (b)and FCCP (c) on state 4 respiration of rat liver mitochondria suspended in a medium containing $50 \mathrm{mM} P_{i}$. Alamethicin concentrations (i) $0.03 \mu \mathrm{M}$, (ii) $0.045 \mu \mathrm{M}$, (iii) $0.075 \mu \mathrm{M}$, (iv) $0.15 \mu \mathrm{M}$, (v) $0.3 \mu \mathrm{M}$. Melittin (i) $0.30 \mu \mathrm{M}$ (ii) $0.5 \mu \mathrm{M}$, (iii) $075 \mu \mathrm{M}$ (iv) $1.5 \mu \mathrm{M}$ (v) $2.25 \mu \mathrm{M}$. FCCP (i) $0.003 \mu \mathrm{M}$, (ii) $001 \mu \mathrm{M}$ (iii) $0.0145 \mu \mathrm{M}$ (iv) $0.018 \mu \mathrm{M}$ (v) $0039 \mu \mathrm{M}$ (vi) $0.051 \mu \mathrm{M}$ (vii) $0.45 \mu \mathrm{M}$. Mito. chondrial protein concentrations (a) $0.49 \mathrm{mg} / \mathrm{ml}$, (b) $0.59 \mathrm{mg} / \mathrm{ml}$ and (c) $064 \mathrm{mg} / \mathrm{ml}$ for i-v and $0.75 \mathrm{mg} / \mathrm{ml}$ for vi and vii. ADP concentrations (a) $110 \mu \mathrm{M}$ (b) $110 \mu \mathrm{M}$ and (c) $124 \mu \mathrm{M}$. All other conditions as described in figure 7.

Leu-Ile-Ser-Trp-Ile-Lys-Arg-Lys-Arg-Gln-Gln-NH ${ }_{2}$ ) and the classical protonophoric uncoupler, carbonylcyanide-p-trifluoromethoxyphenylhydrazone (FCCP), at a $P_{i}$ concentration of $50 \mathrm{mM}$. Melittin is known to form channels in artificial lipid membranes and is therefore expected to uncouple mitochondria (Tosteson and Tosteson, 1981). Alamethicin at a concentration of $0.15 \mu \mathrm{M}$ shows a distinct reduction in $\mathrm{O}_{2}$ consumption rate after an initial stimulation. In contrast, both melittin and FCCP do not show any evidence for a reduction in respiratory rate at the concentration studied.

A constant rate of $\mathrm{O}_{2}$ consumption following peptide addition to state 4 mitochondria results in a linear fall in $\mathrm{O}_{2}$ level with time, until the anaerobic limit is attained. This kind of behaviour is normally observed for classical uncouplers and is seen in figure 8 for melittin and FCCP. Changes in $\mathrm{O}$, consumption rate as a function of time, after uncoupler addition result in non-linear, curved traces. It is useful to analyze this time dependence of $\mathrm{O}_{2}$ consumption rate. The results of such an analysis are shown in figure 9 , for various alamethicin concentrationsat $P_{i}$ concentrations of 2.5 and $50 \mathrm{mM}$. Respiration rates have been measured by taking slopes at different time intervals along the $\mathrm{O}_{2}$ consumption curve. Values have been taken only at points which correspond to total $\mathbf{O}$, concentrations of at least 200 nanogram atoms $/ \mathrm{ml}$. At these levels there is no inherent dependence of respiration rate on total $\mathrm{O}_{2}$ concentration. In the case of $P_{i}=2.5 \mathrm{mM}$, there is a time dependent increase in $\mathrm{O}_{2}$ consumption after peptide addition, at low alamethicin concentrations. For $0.18 \mu \mathrm{M}$ peptide there is an initial increase in respiration rate after addition, followed by a decreased rate of $\mathbf{O}$, consumption which appears at shorter times after peptide addition and also at higher alamethicin concentrations. Figure $9 \mathrm{~b}$ demonstrates a marked difference in the observed behaviour at $P_{i}=\mathrm{SO} \mathrm{mM}$. For alamethicin concentrations below $0.75 \mu \mathrm{M}$ the 

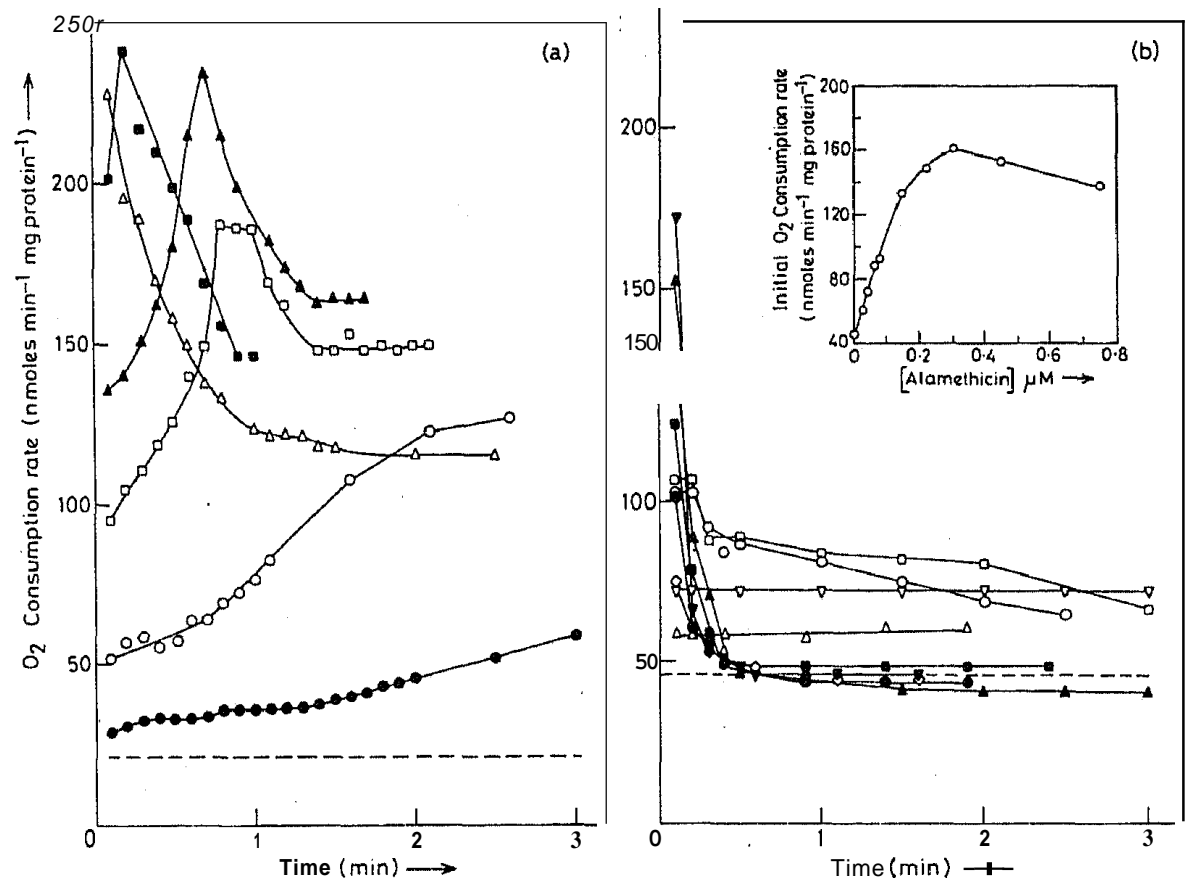

Figure 9. Time dependence of $\mathrm{O}$, consumption rate following alamethicin addition to state 4 mitochondria, (a)Assay medium containing $2.5 \mathrm{mM} \mathrm{KH}{ }_{2} \mathrm{PO}_{4}$, Alamethicin concentra-

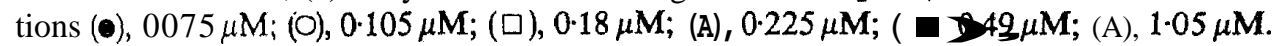
Mitochondria1 protein $0.47 \mathrm{mg} / \mathrm{ml}$. (---) indicates normal state 4 respiration rate. (b) Assay medium containing $50 \mathrm{mM} \mathrm{KK_{2 }} \mathrm{PO}_{4}$. Alamethicin concentrations (A), $0.03 \mu \mathrm{M} ;(\nabla)$, $0.045 \mu \mathrm{M} ;(\square), 0.06 \mu \mathrm{M} ;(0), 0.075 \mu \mathrm{M} ;(\mathrm{A}), 0.15 \mu \mathrm{M} ;(\nabla), 0.225 \mu \mathrm{M} ;(\bullet), 0.30 \mu \mathrm{M} ;(\square), 0.45 \mu \mathrm{M}$; $(\diamond), 0.75 \mu \mathrm{M}$. Mitochondrial protein $0.49 \mathrm{mg} / \mathrm{ml}$. - - indicates normal state 4 respiration rate.Inset: Dependence of $\mathbf{O}$, consumption rate immediately after alamethicin addition (initial slope) on peptide concentration.

respiration rate shows little time dependence, However, at higher peptide concentrations there is a sharp initial enhancement of respiration following peptide addition, with a rapid subsequentdrop in the rate. At an alamethicin level $\gtrsim 0.3 \mu \mathrm{M}$ a drop below the normal state 4 respiration rate is observed, suggestive of an inhibitory effect. Figure $9 \mathrm{~b}$ (inset) shows the influence of alamethicin concentration on the initial $\mathrm{O}_{2}$ consumption rate, measured immediately after peptide addition. The initial rate increases with alamethicin concentration upto $0.3 \mu \mathrm{M}$, while at higher concentrations a decrease sets in.

Phosphate ion concentrations in the medium thus appear to modulate the effects of alamethicin on mitochondrial oxidative phosphorylation. At low $P_{i}$ levels the uncoupling effect presumably arises due to formation of transmembrane channels, which can dissipate the proton electrochemical gradient across the inner mitochondrial membrane. At high $P_{i}$ concentrations $>10 \mathrm{mM}$, mitochondria begin to swell (Hunter and Ford, 1955), with a steady increase in the swelling rate and extent of swelling upto $100 \mathrm{mM}$ (unpublished). Even though lower RCI values are obtained at $100 \mathrm{mM} P_{i}$ $(\sim 4.4)$ as compared to $2.5 \mathrm{mM} P_{i}(\sim 6.7)$, a significant degree of coupling is still obtained at high $P_{i}$ levels. Since mitochondrial swelling follows changes in membrane 
permeabilities, it is reasonable to expect that swelling may also be accompanied by changes in the mobilities and accessibilities of membrane bound components of the electron transport chain. We speculate that the inhibitory action of the peptide, at high $P_{i}$ concentrations, may be due to direct binding to protein components of the electron transport system. Helix macrodipole interactions have been involved to rationalise formation of alamethicin aggregates in lipid bilayers (Mathew and Balaram, 1983b). It is conceivable that such helix dipole-dipole interactions may mediate the binding of helical peptides like alamethicin to transmembrane, helical segments of mitochondria1 membrane proteins. Since uncouplers like FCCP did not reverse the inhibitory effect of alamethicin, the peptide does not appear to act by inhibiting ATP synthetaseactivity. It is pertinent to note that the related polypeptides, efrapeptin (Cross and Kohlbrenner, 1978) and elvapeptin (Bullogh et al., 1982) have been shown to inhibit soluble $F_{1}$ ATPase.

A working hypothesis to rationalize the effects of alamethicin on mitochondria is presented below, which may serve to stimulate the design of further experiments in this area. The initial increase in respiration rate on peptide addition (figure 9) could result from incorporation of alamethicin into the lipid phase followed by channel opening. The subsequent drop in $\mathrm{O}_{2}$ consumption presumably arises due to inhibition of a fraction of respiratory chains, by direct interaction of peptide. The probability of such inhibitory interactions increases with alamethicinconcentration, as evidenced by a shift of the peak in the $\mathrm{O}_{2}$ consumption rate to shorter times after addition of peptide. At high $P_{i}$ concentrations ( $~ \gtrsim 50 \mathrm{mM}$ ) peptide incorporation is very rapid and no peak in respiration rate is observed. The time lag observed for the onset of inhibitory effects is probably determined by the diffusibility of alamethicin molecules in the membrane plane, which is necessary to reach the site of interaction from the site of insertion of the peptide.

Alamethicin and related natural polypeptides provide structurally well defined systems for investigating peptide lipid interactions. Further studies of alamethicin effects on mitochondria may clarify the molecular mechanism underlying the uncoupling and inhibitory effects manifested by this peptide.

\section{Acknowledgements}

We are grateful to Drs. Joseph E. Grady and Richard L. Keene, Upjohn Company, Kalamazoo, Michigan, for a gift of alamethicin. This research was supported by a grant from the Department of Science and Technology. M.K.D. is the recipient of an ICMR fellowship.

\section{References}

Balaram, P. (1983) in Peptides: Structure and Function. Proceedings of the Eighth American Peptide Symposium (eds V. J. Hruby and D. H. Rich) (Rockford,Illinois: Pierce Chemical Company), p 477.

Banerjee, U., Tsui, F. P., Balasubramanian, T. M., Marshall, G. R. and Chan, S. I. (1983)J. Mol. Biol., 165, 757.

Besch, H. R. Jr., Jones, L. R., Fleming, J. W. and Watanabe, A. M. (1977) J. Biol. Chem., 252, 7905.

Bessler, W. G., Ottenbreit, B., Irmscher, G. and Jung, G. (1979) Biochem. Biophys. Res. Commun., 87, 99. 
Boheim, G., Hanke, W. and Jung, G. (1983) Biophys. Struct. Mech., 9, 181.

Bonnafous, J. C., Dornand, J. and Mani, J. C. (1979) Biochem. Biophys. Res. Commun., 86, 536.

Bruckner, H. and Przybylski, M. (1984) J. Chromatogr., 296, 263.

Bullough, D. A., Jackson, C. G., Henderson, P. J. F., Beechey, R. B. and Linnet, P. E. (1982)F EB B Lett., 245, 248.

Chapman, D., Cherry, R. J., Finer, E. G., Hauser, H., Phillips, M. C.,Shipley,G.G. and McMullen, A. I. (1969) Nature (London), 224, 692.

Cross, P. L. and Kohlbrenner, W. E. (1978) J. Biol. Chem., 253,4865.

Finer, E. G., Hauser, H. and Chapman, D. (1969) Chem. Phys. Lipids, 3, 386.

Fox, R. O. Jr. and Richards, F. M. (1982) Nature (London), 300,325.

Green, D. E. (1977)Trends Biochern. Sci., 2, 113.

Hall, J. E. (1978)in Membrane Transport in Biology (eds. G. Giebisch, D. C. Tosteson and H. H. Ussing) (Berlin: Springer-Verlag), Vol. 1, p. 475,

Hauser, H., Finer, E. 6. and Chapman, D. (1970) J. Mol. Biol., 53, 419.

Herman, C. A., Zenser, T. V. and Davis, B. B. (1980) Biochen, Pharmacol., 29, 51.

Hol, W. G. J., Halie, L. M. and Sander, C. (1981) Nature (London), 294, 532.

Hotchkiss, R. D. (1944) Advan. Enzymol., 4, 153.

Hunter, F. E. and Ford, L. (1955) J. Biol. Chem., 216, 357.

Irmscher, G. and Jung, G. (1977) Eur. J. Biochem., 80, 165.

Iqbal, M. and Balaram, P. (1981) Biochemistry, 20, 7278.

Iqbal, M. (1982)Synthetic and spectroscopic studies onfragments of the membrane channel forming polypeptide, suzukacillin and chemotactic tripeptides, $\mathrm{Ph}$. D. Thesis, Indian Institute of Science, Bangalore.

Jones, L. R., Besch, H. R. Jr. and Watanabe, A. M. (1977) J. Biol. Chem., 252, 3315.

Jones, L. R., Maddock, S. W. and Besch, H. R. Jr. (1980)J. Biol. Chem., 255, 9971.

Jung, G., Bruckner, H. and Schmitt, H. (1981)in Structure and Actiuity of Natural Peptides (eds W. Voelter and $\boldsymbol{G}$. Weitzel) (Berlin:Walter de Gruyter), p. 75.

Jung, G., Becker, G.,Schmitt,H., Voges, K. P., Boheim, G. and Griesbach, S. (1983)in Peptides: Structure and Function. Proceedings of the Eighth American Peptide Symposium (eds V. J. Hruby and D. H. Rich) (Rockhord, Illinois: Pierce Chemical Company), p. 491.

Lad, P. J. and White, A. A. (1979) Biochim. Biophys. Acta, 570, 198.

Ladbrooke, B. D. and Chapman, D. (1969) Chem. Phys. Lipids, 3, 304.

Lau, A. L. Y. and Chan, S. I. (1974) Biochemistry, 13,4942.

Lau, A. L. Y. and Chan, S. I. (1975) Proc. Natl. Acad. Sci. USA, 72, 2170.

Lau, A. L. Y. and Chan, S. I. (1976) Biochemistry, 15, 2551.

Mathew, M. K. and Balaram, P. (1983a) Mol. Cell. Biochem., 50, 47.

Mathew, M. K. and Balaram, P. (1983b) FEBS Lett., 157, 1.

Mathew, M. K. and Balaram, P. (1984) Biochim. Biophys. Acta, (in press).

Mathew, M. K., Nagaraj, R. and Balaram, P. (1981a) Biochim. Biophys. Res. Commun, 98, 548.

Mathew, M. K., Nagaraj, R. and Balaram, P. (1981b) Biochim. Biophys. Acta, 649, 336.

Mathew, M. K., Nagaraj, R. and Balaram, P. (1982) J. Biol. Chem., 257, 2170.

Mclntosh, T. J., Ting-Beall, H. P. and Zampighi, G. (1982)Biochim. Biophys. Acta, 685, 51.

Misselwitz, H. J., Will, H., Schulze, W., Will-Shahab, L. and Wollenberger,A. (1979)Biochim. Biophys. Acta, 553, 197.

Mitchell, P. (1966) Biol. Reu., 41, 445.

Monneron, A. and d'Alayer, J. (1980) Biochim. Biophys. Acta, 629, 50.

Moore, C. and Pressman, B. C. (1964) Biochern. Biophys. Res. Commun., 15, 562.

Mueller, P. and Rudin, D. O. (1968) Nature (London),217, 713.

Mueller, P. (1976)in Horizons in Biochemistry and Biophysics (eds E. Quagliariello, F. Palmieri and T. P. Singer) (Reading: Addison-Wesley), Vol. 2, p. 230.

Nagaraj, R. and Balaram, P. (1981) Acc. Chem. Res., 14, 356.

Nagaraj, R., Mathew, M. K. and Balaram, P. (1980)FEBS Lett., 121, 365,

Pedersen, P. L., Greenawalt, J. W., Reynafarje, B., Hullihen, J., Decker, G. L., Soper, J. W. and Bustamente, E. (1978) Meth. Cell. Biol. (ed. D. M. Prescdtt) (New York: Academic Press), Vol. 20, p. 411.

Prasad, B. V. V. and Balaram, P. (1984) CRC. Crit. Revs. Biochem., (in press).

Schmitt, H., Winter, W., Bosch, R. and Jung, G. (1982) Liebigs Ann. Chem., 1304. 
Schwarz, G. and Savko, P. (1982a) Bioelectromagnetics, 3, 25.

Schwarz, G. and Savko, P. (1982b) Biophys. J., 39, 211.

Schwarz, G., Savko, P. and Jung, G. (1983) Biochim. Biophys. Actu, 728, 419.

Shinitzky, M. and Barenholz, Y. (1978) Biochirn. Biophys. Actu, 515, 362.

Smith, G. D., Pletner, V. Z., Duax, W. L., Balasubramanian, T. M., Bosshard, H. E., Czerwinski, E. W., Kendrick, N. C. E., Mathews, F. S. and Marshall, G. R. (1981) J. Am. Chem. Soc., 103, 1493.

Takaishi, Y., Terada, H. and Fujita, T. (1980) Experientia, 36, 550.

Terada, H. (1979) in Cation Flux across Biomembranes (eds Y. Mukoheta and L. Packer) (New York: Academic Press), p. 365.

Terada, H. (1981) Biochim. Biophys. Acta, 639, 225.

Toniolo, C., Bonora, G. M., Bavoso, A., Benedetti, E., DiBlasio, B., Payone, V. and Pedone, C. (1983) Biopolymers, 22, 205.

Tosteson, M. T. and Tosteson, D. C. (1981) Biophys. J., 36, 109.

Wada, A. (1976) Adv. Biophys., 9, 1.

Yantorno, R., Takashima, S. and Mueller, P. (1982) Biophys. J., 38, 105. 